\title{
Total knee arthroplasty infection due to Abiotrophia defectiva
}

\author{
A. INCE, B. TIEMER*, J. GILLE, C. BOOS and M. RUSSLIES \\ Departments of Orthopedics and *Microbiology, Luebeck University Hospital, Ratzeburger Allee 160, 23538 \\ Luebeck, Germany
}

\begin{abstract}
The first documented case of knee alloarthroplasty infection due to Abiotrophia defectiva, formerly known as nutritionally variant streptococci (NVS) and Streptococcus defectivus, is presented. The microbiology of this bacterium is discussed and clinical features of previously reported cases of infections by NVS are reviewed briefly.
\end{abstract}

\section{Introduction}

Abiotrophia defectiva is part of the normal human flora $[1-3]$ and is a resident of the oral cavity $[1,4]$, and the genitourinary and intestinal mucosae $[4,5]$.

Abiotrophia spp. have previously been referred to as nutritionally variant streptococci (NVS) because of their fastidious nutritional growth requirements. Frenkel and Hirsch [6] first isolated these organisms from patients with endocarditis and otitis media. The organisms tend to form satellite colonies around Staphylococcus aureus and other bacteria, including some Enterobacteriaceae and other streptococci. They were described as 'ungroupable' viridans streptococci and required pyridoxal hydrochloride (vitamin $\mathrm{B}_{6}$ ) analogues for growth and produced a chromophore, pyrrolidonyl arylamidase and a bacteriolytic enzyme $[2-4,7,8]$.

Bouvet et al. [2] proposed two new species names for the NVS, Streptococcus defectivus and S. adjacens, on the basis of DNA-DNA hybridisation studies. Analysis of $16 \mathrm{~S}$ ribosomal RNA (rRNA) sequences showed that these two species were not related to other members of the genus Streptococcus. Consequently, they were placed in the new genus Abiotrophia as A. defectiva and $A$. adjacens [9]. A. defectiva differs from $A$. adjacens by the presence of $\alpha$ - and $\beta$-galactosidases and the absence of $\beta$-glucuronidase [7].

Received 3 Dec. 2001; revised version received 22 April 2002; accepted 24 April 2002.

Corresponding author: Dr A. Ince (e-mail: akif_ince@ hotmail.com).
Recently, a third species, A. elegans, has been added to the genus Abiotrophia [10,11]. Lawson et al. [12] described a fourth species, A. balaenopterae, isolated from the lung of a minke whale. Kanamoto et al. [13] proposed the existence of A. para-adjacens.

Recent 16S rRNA gene sequencing studies have demonstrated that the genus is not monophyletic. Phylogenetically, the genus Abiotrophia consists of two distinct lines, A. defectiva and another group consisting of A. adjacens, A. balaenopterae and A. elegans. Therefore, it was proposed by Collins and Lawson that the genus Abiotrophia be restricted to A. defectiva and that $A$. adjacens, $A$. balaenopterae and $A$. elegans be reclassified in a new genus, Granulicatella gen. nov., as $G$. adjacens comb. nov., G. balaenopterae comb. nov. and G. elegans comb. nov. [14].

To draw attention to their clinical significance and difficulties in diagnosis and treatment, this paper describes the first documented case report of an infected total knee alloarthroplasty caused by $A$. defectiva.

\section{Case report}

In April 2000, a 65-year-old woman was admitted to this hospital with progressive pain and swelling in her right knee, which had undergone a total knee arthroplasty (TKA) 4 years earlier. Her medical history included a nephrectomy because of glomerulonephropathy, non-insulin-dependent diabetes mellitus and alcohol abuse in the past.

She was in good general health and reported no fever. Physical examination revealed no abnormalities, in 
particular no port of entry for bacteraemia nor stigmata of endocarditis. Scintigraphy showed evidence of loosening of the prosthesis, and a conventional radiograph was normal. Laboratory data showed a normal white blood count $(5500$ cells $/ \mathrm{ml})$ and elevated Creactive protein $(\mathrm{CRP})(41 \mathrm{mg} / \mathrm{L})$. Aspiration of the right knee yielded $10 \mathrm{ml}$ of turbid fluid. The specimen was injected into agar vials (Venturi Transsystem ${ }^{\circledR}$, Nehren, Germany). A Gram's stain failed to reveal any micro-organisms. Nevertheless, on the basis of the clinical impression, an infection of the total knee arthroplasty was diagnosed.

The patient was taken to surgery for a radical open debridement and replacement of all polyethylene components of the prosthesis. Because no micro-organism had been isolated pre-operatively and no signs of loosening of the prosthesis were seen intra-operatively, the prosthesis was left in place.

Intra-operative aspirates were placed in Bactec plus aerobic and anaerobic culture vials (Becton Dickinson, Sparks, MD, USA). The sample was plated on to Columbia agar supplemented with defibrinated sheep blood 5\% and chocolate agar and incubated aerobically and in an anaerobic atmosphere containing $\mathrm{CO}_{2} 5 \%$ at $37^{\circ} \mathrm{C}$. Several small $\alpha$-haemolytic colonies were noted on the blood-agar plate after incubation for $24 \mathrm{~h}$. Gram's stain revealed pleomorphic gram-positive coccobacilli. The bacterium was not identified with a rapid identification system for gram-positive rods (API Coryne; bioMérieux, Marcy l'Etoile, France) after incubation for $12 \mathrm{~h}$, nor was it identified by rapid identification systems for streptococci (Rapid ID 32 STREP, bioMérieux) after incubation for $4 \mathrm{~h}$. The bacterium was identified with a universal PCR system, with primers targeting part of the 16S rDNA [15]. The amplified PCR product was sequenced and a BLAST search at the NCBI was performed [16]. A. defectiva was identified, with a homology of $99.9 \%$.

Antimicrobial treatment included cefazolin i.v. for 10 days, followed by ciprofloxacin orally for 26 days until CRP levels and the physical examination returned to normal.

In July 2000 the patient presented again with pain and swelling as signs of an infected knee prosthesis. Gram's staining of the aspirated intra-articular fluid showed pleomorphic gram-positive coccobacilli and samples plated on to Columbia agar with defibrinated sheep blood 5\% grew small $\alpha$-haemolytic colonies.

As Abiotrophia was considered to be the possible causative agent, a rapid ID 32 STREP test (bioMérieux) was performed. After $12 \mathrm{~h}$ the biochemical reactions exhibited the characteristic patterns of $A$. defectiva. This prolonged incubation $(12 \mathrm{~h}$ instead of
$4 \mathrm{~h}$ ) was necessary because of the long generation time of Abiotrophia.

A two-stage revision arthroplasty was performed. After debridement and explantation, antibiotic treatment was initiated with ciprofloxacin i.v. As the patient developed profuse diarrhoea, the regimen was changed to penicillin i.v. and subsequently to flucloxacillin orally until the CRP level returned to normal. In December 2000 a new alloarthroplasty was implanted. At present the patient has good function of the TKA.

\section{Discussion}

A. defectiva and A. adjacens account for 5-6\% of cases of streptococcal endocarditis and some authors have suggested that they are an important cause of blood culture-negative endocarditis [17-21]. Bouvet [22] isolated two strains of $S$. adjacens and five strains of $S$. defectivus from 91 strains of viridans streptococci that caused endocarditis. Some authors noted that the clinical course was often more severe than in cases of endocarditis caused by other viridans streptococci or enterococci [23, 24].

Ormerod et al. [25] described four cases of infectious crystalline keratopathy caused by NVS. Recently, it has been shown that infiltrative keratitis can be associated with $A$. defectiva [26]. Wofsy [27] reported a case of joint infection caused by NVS as a complication of endocarditis. These organisms have also been implicated in pancreatic abscess, otitis media, wound infections and iatrogenic meningitis [28, 29].

Therapeutic failure occured in $41 \%$ and relapse in $17 \%$ of endocarditis cases, despite treatment with antibiotics that appeared to be active in vitro [23]. Stein and Nelson [23] hypothesised that the difficulties in treatment may be caused by the slow growth rate and suggested that a longer course of antibiotic therapy may be required for successful treatment of cases of NVS endocarditis.

Exopolysaccharide production by NVS in later stages of rabbit endocarditis has been reported. It was suggested that nutrient limitation within vegetations could account for altered ultrastructural morphology and that exopolysaccharide might enhance NVS pathogenicity [4]. The frequent colonisation and infection of cardiac valves with Abiotrophia spp. suggests an affinity for avascular tissue, as found around an alloarthroplasty.

The reported incidence of knee alloarthroplasty infections ranges from $0 \%$ to $23 \%$ with an average of $5 \%$ [30] and is caused by direct spread or by haematogenous spread. Staphylococci are the major causative agents of this type of infection, followed in descending order by gram-positive aerobic streptococci, gramnegative aerobes and anaerobes [31]. The authors 
believe that, in the past, arthroplasty infections with NVS have included Abiotrophia spps, which were uncharacterised at that time. The treatment of arthroplasty infections includes repetitive debridements [32], removal of the prosthesis and leaving an excision arthroplasty [33] and converting to an arthrodesis [34-36]. A two-stage revision arthroplasty leaving a temporary spacer of bone cement containing antibiotics has become more common $[37,38]$.

In the case reported here, the isolate of $A$. defectiva was susceptible in vitro (disk diffusion tests on Mueller-Hinton agar with defibrinated sheep blood $5 \%$ ) to penicillin, clindamycin, cefazolin, cefpodoxime, cefuroxime, cefotaxime, gentamicin, ciprofloxacin and imipenem and resistant to tobramycin, doxycycline and aztreonam. The susceptibility of 27 $G$. adjacens and $12 \mathrm{~A}$. defectiva isolates was investigated by a microdilution method with pyridoxal hydrochloride and Mueller-Hinton broth supplemented with lysed horse blood. According to NCCLS interpretative criteria for Streptococcus spp. not $S$. pneumoniae, the susceptibilities of $G$. adjacens and A. defectiva strains were, respectively: penicillin, 55\% and $8 \%$; amoxicillin, $81 \%$ and $92 \%$; ceftriaxone, $63 \%$ and $83 \%$; meropenem, $96 \%$ and $100 \%$; and $100 \%$ for both species with clindamycin, rifampin, levofloxacin, ofloxacin, quinupristin/dalfopristin and vancomycin [39].

High-level resistance to aminoglycosides (MIC $>500$ $\mathrm{mg} / \mathrm{L}$ ), as encountered with enterococci and viridans streptococci, has not been reported for NVS. Synergy between penicillin or vancomycin in combination with an aminoglycoside has been observed both in vitro and in experimental animal models of endocarditis [40]. However, in-vitro antimicrobial susceptibility testing of Abiotrophia is not standardised, and the results of invitro susceptibility tests do not correlate well with clinical effectiveness.

In conclusion, $A$. defectiva is a relatively unknown micro-organism, which may cause serious infections including culture-negative forms of alloarthroplasty infection and endocarditis.

The extreme pleomorphic appearance of strains may be confusing and cause diagnostic problems [30], which could lead to prolonged morbidity and costly diagnostic and therapeutic procedures. If Gram's stain indicates gram-positive cocci in chains or pairs, the addition of pyridoxal-containing medium or cross-inoculation of the inoculated plate with Staph. aureus may increase detection of Abiotrophia isolates. Also, because of the slow growth rate of Abiotrophia spp., prolonged incubation for at least $72 \mathrm{~h}$ in an atmosphere containing $\mathrm{CO}_{2} 5-10 \%$ is recommended.

Clinicians and microbiologists should be aware of this organism and its pathogenic potential.

\section{References}

1. Georg RH. The isolation of symbiotic streptococci. J Med Microbiol 1974; 7: 77-83.

2. Bouvet A, Grimont F, Grimon PAD. Streptococcus defectivus sp. nov. and Streptococcus adjacens sp. nov., nutritionally variant streptococci from human clinical specimens. Int J Syst Bacteriol 1989; 39: 290-294.

3. Pompei R, Caredda E, Piras V, Serra C, Pintus L. Production of bacteriolytic activity in the oral cavity by nutritionally variant streptococci. J Clin Microbiol 1990; 28: 1623-1627.

4. Ruoff KL. Nutritionally variant streptococci. Clin Microbiol Rev 1991; 4: 184-190.

5. McCarthy LR, Bottone EJ. Bacteremia and endocarditis caused by satelliting streptococci. Am J Clin Pathol 1974; 16: 585-591.

6. Frenkel A, Hirsch W. Spontaneous development of L forms of streptococci requiring secretions of other bacteria or sulphydryl compounds for normal growth. Nature 1961; 191: 728-730.

7. Bouvet A, Villeroy F, Cheng F, Lamesch C, Williamson R, Gutmann L. Characterization of nutritionally variant streptococci by biochemical tests and penicillin-binding proteins. $J$ Clin Microbiol 1985; 22: 1030-1034.

8. Kanamato TH, Eifuku-Koreeda H, Inoue M. Isolation and properties of bacteriolytic enzyme-producing cocci from the human mouth. FEMS Microbiol Lett 1996; 144: 135-140.

9. Kawamura Y, Hou XG, Sultana F, Liu S, Yamamoto H, Ezaki T. Transfer of Streptococcus adjacens and Streptococcus defectivus to Abiotrophia gen. nov. as Abiotrophia adiacens comb. nov. and Abiotrophia defectiva comb. nov., respectively. Int J Syst Bacteriol 1995; 45: 798-803.

10. Roggenkamp A, Abele-Horn M, Trebesius K-H, Tretter U, Autenrieth IB, Heesemann J. Abiotrophia elegans sp. nov., a possible pathogen in patients with culture-negative endocarditis. J Clin Microbiol 1998; 36: 100-104.

11. Roggenkamp A, Leitritz L, Baus K, Falsen E, Heesemann J. PCR for detection and identification of Abiotrophia spp. J Clin Microbiol 1998; 36: 2844-2846.

12. Lawson PA, Foster G, Falsen E, Sjödén B, Collins MD. Abiotrophia balaenopterae sp. nov., isolated from the minke whale (Balaenoptera acutorostrata). Int J Syst Bacteriol 1999; 49: $503-506$.

13. Kanamoto T, Sato S, Inoue M. Genetic heterogeneities and phenotypic characteristics of strains of the genus Abiotrophia and proposal of Abiotrophia para-adjacens sp. nov. $J$ Clin Microbiol 2000; 38: 492-498.

14. Collins MD, Lawson PA. The genus Abiotrophia (Kawamura et al.) is not monophyletic: proposal of Granulicatella gen. nov., Granulicatella adjacens comb. nov., Granulicatella elegans comb. nov. and Granulicatella balaenopterae comb. nov. Int J Syst Evol Microbiol 2000; 50: 365-369.

15. Greisen K, Loeffelholz M, Purhoit A, Loeng D. PCR primers and probes for the $16 \mathrm{~S}$ rRNA gene of most species of pathogenic bacteria, including bacteria found in cerebrospinal fluid. J Clin Microbiol 1994; 32: 335-351.

16. Altschul SF, Madden TL, Schäffer AA et al. Gapped BLAST and PSI-BLAST: a new generation of protein database search programs. Nucleic Acids Res 1997; 25: 3389-3402.

17. Roberts RB, Krieger AG, Schiller NL, Gross KC. Viridans streptococcal endocarditis: the role of various species, including pyridoxal-dependent streptococci. Rev Infect Dis 1979; 1: 955-965.

18. Christensen JJ, Gruhn N, Facklam RR. Endocarditis caused by Abiotrophia species. Scand J Infect Dis 1999; 31: 210-212.

19. Poyart C, Quesne G, Acar P, Berche P, Trieu-Cuot P. Characterization of the Tn916-like transposon Tn3872 in a strain of Abiotrophia defectiva (Streptococcus defectivus) causing sequential episodes of endocarditis in a child. Antimicrobial Agents Chemother 2000; 44: 790-793.

20. Boutoille D, Reynaud AE, Leautez S, Ponge T, Raffi F. [Abiotrophia related endocarditis: contribution of molecular biology.] Presse Med 1999; 28: 2149-2151.

21. Bouvet A. Human endocarditis due to nutritionally variant streptococci: Streptococcus adjacens and Streptococcus defectivus. Eur Heart J 1995; 16: 24-27.

22. Bouvet A. Endocardite infectieuse: enquete en France 19901991 - Sensibilite aux antibiotiques des streptocoques et enterocoques. Med Mal Infect 1992; 22S: 987-992.

23. Stein DS, Nelson KE. Endocarditis due to nutritionally 
deficient streptococci: therapeutic dilemma. Rev Infect Dis 1987; 9: 908-916.

24. Roberts RB, Wilson WR, Bouvet A, Acar JF. Nutritionally variant streptococcal endocarditis. International Conference of Antimicrobial Agents and Chemotherapy, 1982: abstract no. 82.

25. Ormerod LD, Ruoff KL, Meisler DM et al. Infectious crystalline keratopathy. Role of nutritionally variant streptococci and other bacterial factors. Ophthalmology 1991; 98: $159-169$.

26. Keay L, Harmis N, Corrigan K, Sweeney D, Willcox M. Infiltrative keratitis associated with extended wear of hydrogel lenses and Abiotrophia defectiva. Cornea 2000; 19: 864-869.

27. Wofsy D. Culture-negative septic arthritis and bacterial endocarditis. Diagnosis by synovial biopsy. Arthritis Rheum 1980; 23: 605-607.

28. Carey RB, Gross KC, Roberts RB. Vitamin $B_{6}$-dependent Streptococcus mitior (mitis) isolated from patients with systemic infections. J Infect Dis 1975; 131: 722-726.

29. Bottone EJ, Thomas CA, Lindquist D, Janda JM. Difficulties encountered in identification of a nutritionally deficient Streptococcus on the basis of its failure to revert to streptococcal morphology. J Clin Microbiol 1995; 33: 1022-1024.

30. Insall JN (ed). Surgery of the knee. New York: Churchill Livingstone. 1984.

31. Brause BD. Infected orthopedic prostheses. In: Bisno AL, Waldvogel FA (eds) Infections associated with indwelling medical devices. Washington, DC, American Society for
Microbiology. 1989: 111-127.

32. Morrey BF, Westholm F, Schoifet S, Rand JA, Bryan RS. Long term results of various treatment options for infected total knee arthroplasty. Clin Orthop 1989; 248: 120-128.

33. Falahee MH, Matthews LS, Kaufer H. Resection arthroplasty as a salvage procedure for a knee with infection after a total arthroplasty. J Bone Joint Surg [Am] 1987; 69: 1013-1021.

34. Chapchal G. Intramedullary pinning for arthrodesis of the knee joint. J Bone Joint Surg [Am] 1948; 30: 728-734.

35. Charnley JC. Positive pressure in arthrodesis of the knee joint. $J$ Bone Joint Surg [Br] 1948; 30: 479-486.

36. Fahmy NRM, Barnes KL, Noble J. A technique for difficult arthrodesis of the knee. J Bone Joint Surg [Br] 1984; 66: 367-370.

37. Rand JA, Bryan RS. Reimplantation for the salvage of an infected total knee arthroplasty. J Bone Joint Surg [Am] 1983; 65: $1081-1086$.

38. Windsor RE, Insall JN, Urs WK, Miller DV, Brause BD. Twostage reimplantation for the salvage of total knee arthroplasty complicated by infection. J Bone Joint Surg [Am] 1990; 72: $272-278$.

39. Tuohy MJ, Procop GW, Washington JA. Antimicrobial susceptibility of Abiotrophia adjacens and Abiotrophia defectiva. Diagn Microbiol Infect Dis 2000; 38: 189-191.

40. Mandell GL, Bennett JE, Dolin R. Principle and practice of infectious diseases, 5th edn. New York, Churchill Livingstone. 2000: 2172-2173. 